Management Dynamics

Vol. 23, No. 2: 229-242, 2020

Shanker Dev Campus

Doi: https://doi.org/10.3126/md.v23i2.35824

\title{
Consumer's Motivation to Purchase Frozen Food in Kathmandu
}

\begin{abstract}
The purpose of the current study is to identify the motivating factors in purchasing frozen food in Kathmandu. Frozen food is considered one of the growing food industry, and bears the ability to sustain itself in today's market. The research used casual-comparative and descriptive research design with a quantitative and qualitative approach to get an in-depth understanding of the subject matter. The convenience sampling technique was to collect the data where 156 samples were collected using a survey questionnaire from the consumer who bought frozen food from the department store in the Balaju area of Kathmandu. Along with this in-depth interview was taken with the store representative to find out the highly preferable frozen food. A test of ANOVA was run to understand the relationship between demographic variables and motivation factors and purchase intention. The correlation coefficient was used to test the relationship between dependent and independent variables. Research findings reveal that there is no significant relationship between age, gender, and employment status on motivation factor and purchase intention, however, the finding revealed that there is a significant relationship between education and purchase intention. Similarly, the research uncovered that the consumer's motivation in regards to purchasing frozen food is highly dependent on intrinsic factors (taste, ingredients, nutritional value, value for money), and extrinsic factors (brand, advertisement, convenience, education). Along with this study also revealed on a household, the most purchase frozen food product is frozen MO: MO and on industrial related with the restaurant and hotels, the most purchased frozen food product is the frozen green peas, French fries, and sweet corn.
\end{abstract}

Keywords: Extrinsic motivation, intrinsic motivation, purchase intention, brand.

\section{Background of the study}

Frozen food is prepared by the freezing process and its market is growing significantly, as it is convenient and ready to cook. Food taste and flavor are not affected by the freezing process due to which consumers are more attracted to it. It has become a perfect choice for the people who are prone to a busy schedule and who don't like to spend much time in the kitchen (Jay, 2000). According to the encyclopedia;

\footnotetext{
*Lecturer, Lumbini Academy, Tribhuvan University, E-mail: dabadi@hotmail.com

** Independent Researcher, E-mail: Binitebgurung@gmail.com
} 
The process of freezing food has been employed by people in the Arctic in prehistoric times. Eskimos throw fresh-caught fish on the ice to freeze, and naturally, frozen fish have been a trade staple of the Great Lakes region of North America since the mid-19th cent. Brine and cold-room convection methods were in use in Europe and the United States from about 1860 for freezing meat, fish, poultry, and eggs. In the early part of the 20th century, small fruits were frozen for manufacturers of preserves, bakery products, and ice cream.

The frozen food market in India has been increasing by 30\% per year (Solanki \& Seth, 2015). Similarly, the market of frozen food in Nepal is growing, and the market is at its peak due to the pandemic. The interest of the consumer towards frozen food has increased as the people fear to go outside their house. The demand for frozen food from restaurants had been increasing steadily until the lockdown forced them to close. However, now frozen foods are becoming very popular among retail buyers. "Similarly the supermarket like Bhat Bhateni and Sales berry has observed huge demand for frozen food. Likewise, the orders from hotels and restaurants have gone down, but supermarkets are ordering more. (https:/ / kathmandupost. com/moneylockdown-leads-to-sales-boom-in-frozen-foods)

Consumers are more attracted to frozen food due to their convenience, value, attractive appearance, taste, and texture (Patel \& Rathod, 2017). The food remains fresh when it is frozen this is the reason why people are attracted to it. According to Olson and Dietrich (1969), properly blanched, frozen, and packaged vegetables including cauliflower, green beans, peas, and spinach can be kept at $-29^{\circ} \mathrm{C}$ for 5 years without measurable change in color, flavor, chemical constituents, and physical attributes.

Factors such as age, gender, wage education, and inclination play an important role in the client purchase decision (Kotler, et.al, 2001). In Nepal, there is a difference in income, education, and lifestyle among the residents of the cities, so the markets are forced to challenge the increased awareness and teach the potential of frozen foods products. Besides these difficulties, consumers of frozen food are increasing therefore the current research paper aims at identifying the effect of demographic variables and the motivation factors that influence the purchase intention of frozen food in Kathmandu.

\section{Literature review}

The Theory of buying behavior was initially introduced by the economist (Cooper \& Channon, 1998). Similarly, Maslow theorizes Maslow's Hierarchy of Needs (Maslow, 1943) which envisages a pyramid-shaped arrangement of needs, the theory is used by marketers to identify consumer needs and wants. Nevertheless, it is not practical in the changing need of a changing society. It is very difficult to understand consumer buying decision because consumers' behavior and consumer needs are interrelated in this perception, and attitude plays a big role, regarding this (Bettman, 1979) explained external and internal memory plays a vital role in buying behavior where actual experience is called internal memory, while information related to goods or service is called external memory. 
Gosh, (1990) said a purchase intention is an effective tool used in predicting the purchasing process similarly; purchase intention might be altered by the influence of price, quality perception and, value perception (Zeithaml, 1998). Change is inevitable and our societal formation is ever-changing so many unidentified entities might affect the buying behavior. While purchasing in the department store most of the consumer display impulsive buying behavior where the packaging, advertisement, display plays a greater role. The research done in India proved that shopping behavior and impulse buying is emerging as a highly noticeable behavior due to entries of foreign products in the Indian market, growth in the organized retail industry, increasing disposable income, favorable demographic segmentation, and changing culture \& lifestyle (Muruganantham \& Bhakat, 2013).

The same situation is reflected in the city area of Nepal as well, along with this instinct and the external environment plays a greater role in making a decision. Consumer behavior is stimulated by the physiological motivation that inspires them to purchase in the retail store to fulfill their need (Kim \& Jin, 2001). In addition to it (Elizabeth, 1996) claimed that buying behavior is influenced by the various psychological process and personality traits. Consumer buying decision starts with a need recognition and ends up with the divestment process.

\section{Demographic factor and the purchase intention}

Gender plays a significant role in purchasing behavior, women spent more time while shopping than men (Darley and Smith 1995), but this view now contradicts as the women roles are changing in society. The demand for frozen food might have increased because of the women changing roles, and their participation in labor activity, working hours, and household income (Ahuja, 2011). Age also plays a significant role in the purchase decision, along with these eating habits changes with age. Rani (2014) states the socio-demographic factors such as age, gender, annual income, occupation, economic condition plays a significant role in a purchase decision. This view paralleled with the current study. Employment status also affects the purchasing intention of a food item; different professions may have a different choice. Full-time workers should emphasize timesaving attributes and engage in timesaving behaviors (Becker 1965). Vasegh and Kazemi (2015) in their study found that the behavior of consumers buying dairy products in terms of employment status, marital status, and education level are significant. This can be true with the purchasing of frozen food.

\section{Motivation and purchase intention}

Cummins (2002) studied the price of frozen foods and greater availability in Glasgow, the study discovered that consumers are not affected by the price and the availability of the food if the food is beneficial to health they prefer to purchase them as the risk compared to the price relatively worth it. Hansen (2000) did a comparative study of American and Canadian consumers on 'buying decisions for frozen food products', the study is based on two consumer theories, the theory of explanatory action and the theory of planned behavior. The results suggest that pre-planned decisions were seen as a majority. Similarly, Schroter (2006) after developing the model to identify conditions under which price and income would affect the buying behavior of groceries. The finding suggested that people would purchase frozen 
food rather than fast food because of the health benefit associated with it furthermore study claimed that due to the rise in obesity and inflation consumer choose to buy frozen foods irrespective of the prices and the less quantity. Buyer's beliefs and states of mind construct a brand picture, this will affect their perception toward brands, and how they encounter (Kotler, Burton, Deans, Brown \& Armstrong, 2013) determines the purchase decision. Still, Hibić and Poturak (2016) found there is a high impact of branding on consumer decisionmaking processes and their purchasing decisions.

Literature reports that customers evaluate information about product features, quality, category, and available brands before buying (Belch \& Belch, 1998 ; Bughin, Doogan, \& Vetvik, 2010), which support the current study's point of view. Similarly, customers show positive intention towards the purchase of products about which they have sufficient knowledge (Alba, 1983; Vaughn, 1980), and this can also be true for frozen food products

Awareness with the brand, extrinsic cues (such as price and package), perceived quality variation, perceived risk, and perceived value for money, income, and family size are examples of factors influencing consumers' product choice behavior Dick, Jain, and Richardson (1996).

While purchasing food items taste matters a lot, when consumers are given choice between taste and price consumers go for taste. The study on Croatia about organic food reveals that women find organic products tastier than men (Radman, 2005). However, some western European studies indicated that taste is one of the main buying motives for men. (Hofmann, 2006).

Consumer knowledge regarding the food and the brand plays a crucial role in purchasing food items once they collect information about the product they decide to purchase them according to their need. Consumer buys the product according to their knowledge about the product many research claims that highly educated consumers have better product knowledge (Zanoli, 2004). Similarly, sufficient knowledge about the product has a positive effect on purchase intention (Alba, 1983; \&Vaughan, 1980). This can be considered true for frozen food as well. The information about the products can be collected from different modes of advertisement. Ramasamy, Kalaivavan, \& Sukumar (2005) in their study found that the buying behavior is hugely influenced by awareness and brand image of the product and further claimed television advertisement is the most important source of information followed by display in retail outlets. Along with this Wardle, Steptoe, and Oliver (2000) highlighted that knowledge about food nutrition was closely related to food purchase.

Without proper equipment frozen food industry cannot sustain so technological development is very important. Clarence Birdseye was the first to develop blast-freezing technology in the 20th century that preserved both taste and appearance. The idea behind it is when food is frozen fast, large ice crystals are unable to form, whereas, in the normal process of freezing, large ice crystals are formed that can damage and affect the flavor and texture of foods (Archer, 2004). 


\section{Research Gap}

Despite overall market growth, sales have remained tepid in recent years. Frozen food brands face ongoing challenges, as consumer preferences shift, competition increases, and lack of awareness. While frozen foods are appealing for consumers who value ease and convenience, and many consumers prefer the fresh, natural foods found in the perimeter of the grocery store. Many consumers believe that fresh foods are healthier and of higher quality than items in the freezer aisle. As incomes increase consumers tend to buy more fresh produce and dine out more often, rather than heating frozen meals at home. Also, consumers now have more high-quality prepared meals readily available from a variety of outlets, because of these health concerns, consumers have purchased fewer frozen foods, and industry revenue rose only slightly in the past few years.

In the Nepalese food market, the same concept applies to every consumer, the lack of awareness and the marketing agenda has caused a great loss in the frozen food business. Many consumers assume that frozen food contains a very high amount of preservatives in which case it is false whereas freezing the food reduces the need for additives and helps preserve the food.

In Nepal, there are not many food, and health and safety regulations in practice and rules regarding the punishments for the abuse of chemicals in food. The lack of law in practice puts in danger for the consumer market for frozen food. The passing around of false information and rumors has played a loss in the market of frozen food and plays a vital role in consumer behavior for frozen food.

- To identify the role of intrinsic motivation factor towards the purchase intention of frozen food.

- To identify the role of extrinsic motivation factor towards the purchase intention of frozen food

- To analyze the effect of a demographic variable on motivation factors and the purchase intention.

\section{Research Hypothesis and Conceptual Framework of Study}

H1: There is a significant relationship between intrinsic motivations and purchase intention of frozen food

H2: There is a significant relationship between extrinsic motivation and purchase intention of frozen food

H3: Age plays a significant role in the purchase intention of frozen food

H4: Gender plays a significant role in the purchase intention of frozen food

H5: Employment status plays a significant role in and purchase intention of frozen food

H6: Education plays a significant role in the purchase intention of frozen food 


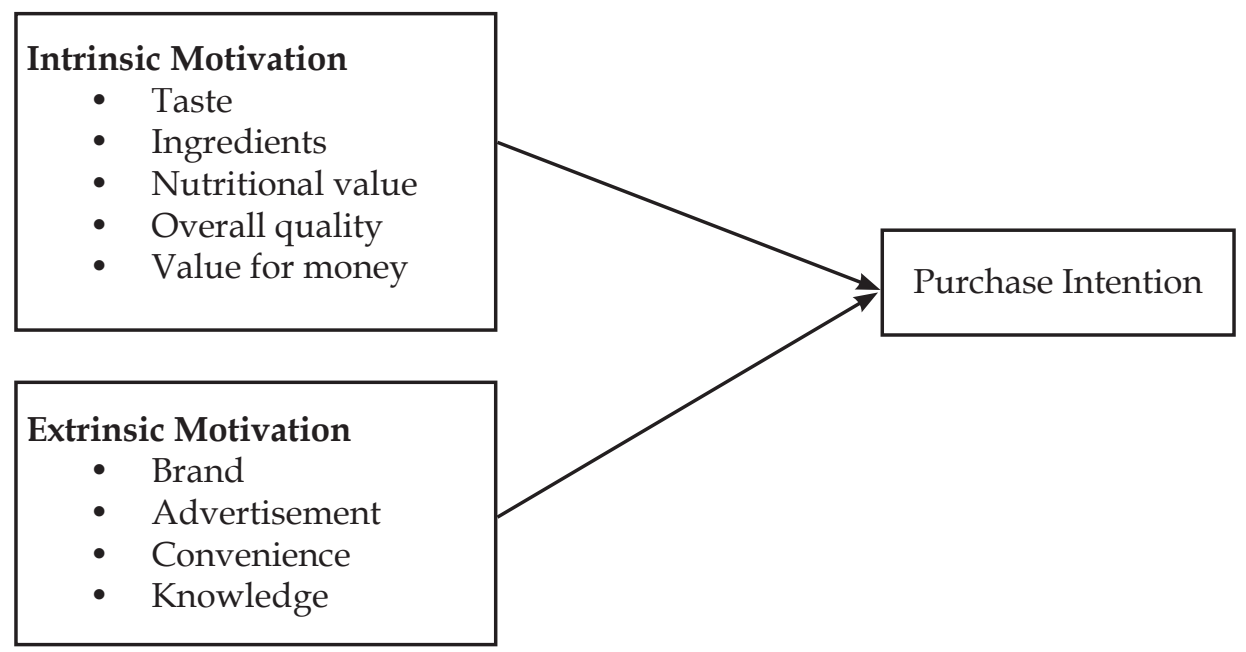

\section{Research Methodology}

The current research uses casual-comparative and descriptive research design using a quantitative and qualitative approach to meet the research objective. The quantitative approach is used to quantify the assumed relationship between the dependent variables and independent variables, whereas the qualitative approach provides an in-depth understanding of the matter. To find the solution to the research problem, the researcher collected the data from the people who have purchased frozen food in the department store (Bhatbhateni and Salesberry) in the Balaju area. The population of the study is unknown; the convenience sampling technique was used to collect the data. The primary data was collected using a survey questionnaire and in-depth interviews with a store representative. The researcher itself was present during the data collection and the questionnaire was handed over to those consumers who bought frozen food items. An interview with the store representative was also taken. The collected data was interpreted using statistical packages for social science (SPSS) software. The study needed to find out the relationship between dependent and independent variables, for this Pearson correlation, Chi-square, and ANOVA test was run. 
Results and Discussion respondents profile

Table 1: Respondent Information

\begin{tabular}{|l|l|c|c|}
\hline \multicolumn{1}{|c|}{ Variable } & \multicolumn{1}{|c|}{ Category } & Frequency & Percentage \\
\hline Respondents Gender & Female & 90 & 57.7 \\
& Male & 66 & 42.3 \\
\hline Respondent by age & below 20 & 18 & 11.5 \\
& $21-25$ & 98 & 62.8 \\
& $26-35$ & 33 & 21.2 \\
& 35 above & 7 & 4.5 \\
\hline Respondents by profession & Employed & 100 & 64.1 \\
& Unemployed & 56 & 35.9 \\
\hline Respondents by education level & High school & 18 & 11.5 \\
& Bachelors & 109 & 69.9 \\
& Masters & 28 & 17.9 \\
& PhD & 1 & .6 \\
\hline Respondents by number of times & $1-3$ & 45 & 35.3 \\
they shop at department shop in & $4-6$ & 25 & 30.8 \\
months & $7-9$ & 28 & 16.0 \\
& 10 above & 36.9 \\
\hline Respondents by number of times & every week & 93 & 23.1 \\
they purchase frozen food & every month & 27 & 17.3 \\
\hline Revpondents by the preference for & Frozen food from the & 37 & 23.7 \\
\cline { 2 - 5 } frozen food or fresh food & department store & & \\
& Fresh food from the & 119 & 76.3 \\
& local vendors & & \\
\hline
\end{tabular}

Table shows respondents' male respondent has found to be 42.3 percent and femalerespondents have recorded to be 57.7 percent. Thus, it concludes that the majority of respondents were female $(57.7 \%)$. As per the age group. Here the data represents 62.8 percent were from the age group of twenty-one to twenty-five with the highest majority of the age group and the seven percent were above 35. Data on employment status revealed that. The employed ratio is the highest with 64.1 and the unemployed ratio is 35.9 percent. Most the respondent has a bachelor degree with 69.9 percent and the lowest in the Ph.D. with 0.6 percent.

The response to the statement, how often do people purchase the frozen food products every month, one to three times has 35.3 percent having the highest majority, four to six-times has 30.8 percent, seven to nine times a month has $16 \%$ with the least and ten and above with 17.9 percent. 
Here the data present that the ratio of people preferring fresh food products is more 76.3 percent than that of people preferring frozen food products 23.7 percent.

Table 2: Test of ANOVA

\begin{tabular}{|l|c|c|c|c|}
\hline \multicolumn{1}{|c|}{ S.N } & & Extrinsic & Intrinsic & Purchase Intention \\
\hline 1 & Gender & 0.402 & 0.260 & 0.173 \\
\hline 2 & Age & 0.023 & 0.030 & 0.069 \\
\hline 3 & Education & 0.098 & 0.092 & 0.012 \\
\hline 4 & Employment Status & 0.009 & 0.135 & 0.690 \\
\hline
\end{tabular}

Table 2 shows test of ANOVA was used to calculate the p-value of the demographic variable the result indicates p-value of gender for the extrinsic and intrinsic variable is 0.402 and 0.260 at 95 percent level of confidence respectively implied that the null hypothesis is not rejected. Similarly, in purchase intention is p-value is 0.173 this also specifies that the null hypothesis should not be rejected. In other words, it indicates that there no statistically significant relationship between gender, motivation factors, and purchase intention of frozen food. Whereas in the case of age the p-value of extrinsic and intrinsic motivation factor is 0.023 and 0.030 respectively this indicated that the null hypothesis should be accepted the result signifies, there is a statistically significant relationship between age and motivation factors, whereas the p-value of 0.069 of purchase intention determines there is no significant relationship between age and purchase intention.

The statistical relationship of education with motivation factor and the purchase intention specifies that the p-value is more than 0.05 in the motivation factors, which means the null hypothesis is not rejected whereas the p-value for purchase intention is less than 0.05 , which means the null hypothesis is rejected. In other words, there is no statistically significant relationship between education and motivation factors, but there is a significant relationship between education and purchase intention.

The p-value of extrinsic is 0.009 , which means there is a significant relationship between employment status and extrinsic motivation whereas the p-value of 0.135 of intrinsic motivation factor proves that there is no significant relationship between and intrinsic motivation factor for employment status. Similarly, a p-value of is 0.690 indicates that there is no significant relationship between employment status and purchase intention. 
Table 3: Descriptive Statistics of Intrinsic Motivation

\begin{tabular}{lr|r|r|r|r}
\hline & & & & & $\begin{array}{c}\text { Std. } \\
\text { Deviation }\end{array}$ \\
\hline Taste & 156 & 1.00 & 5.00 & 2.2244 & 1.26273 \\
\hline Nutritional Value & 156 & 1.00 & 5.00 & 2.7372 & 1.29072 \\
\hline Ingredients & 156 & 1.00 & 5.00 & 2.2436 & 1.14932 \\
\hline quality & 156 & 1.00 & 5.00 & 1.9231 & 1.28785 \\
\hline Value for Money & 156 & 1.00 & 5.00 & 2.3462 & 1.20029 \\
\hline
\end{tabular}

To measure the intrinsic motivation factor five indicators were used and tested. From the analysis, it is found that the mean value of quality was 1.9231, which indicates the consumers are affected by the quality to get intrinsically motivated. The mean value of $2.2244,2.7372$, 2.2436, and 2.3462 indicated that intrinsic motivation factors for purchasing frozen food have a significant impact on taste, nutritional value, ingredients, and value for money.

Table 4: Descriptive Statistics of Extrinsic Motivation

\begin{tabular}{l|r|r|r|r|r}
\hline & & & & & $\begin{array}{c}\text { Std. } \\
\text { Deviation }\end{array}$ \\
\hline Knowledge & 156 & 1.00 & 5.00 & 2.3910 & 1.08701 \\
\hline Advertisement & 156 & 1.00 & 5.00 & 2.6795 & 1.35355 \\
\hline Convenience & 156 & 1.00 & 5.00 & 2.5897 & 1.15771 \\
\hline Brand & 156 & 1.00 & 5.00 & 2.1923 & 1.27565 \\
\hline
\end{tabular}

To measure the extrinsic motivation factor four indicators were used namely Knowledge, Advertisement, Convenience, and Brand, the mean value for the variable are 2.3910, 2.6795, 2.5897 and 2.1923 indicates that extrinsic motivation factor for purchasing frozen food has a significant impact on Knowledge, Advertisement, Convenience, and Brand.

\section{Key Informants interview}

The informants said the most preferable frozen food item is MO: MO on the household, where the consumer seeks for a brand, and taste. The informants further mentioned that it is convenient and saves time. The demand increased due to COVID-19, people were scared to visit a restaurant so instead, and they purchase Frozen MO: MO and enjoy with the family. On an industrial basis, such as hotels, restaurants, and guest houses the highly purchased items are frozen green peas, French fries, and sweetcorn which determine the availability of the product all the time and the convenience it provides along with the time saving and less labor-intensive. 


\section{Co-relation}

Finally, to examine the statistical level of the significance of the relationship between the various dependent and independent variables considered in the present research, the information pertaining to the correlation between these variables are presented in the table below.

\begin{tabular}{|c|c|c|c|c|}
\hline & & $\begin{array}{l}\text { Extrinsic } \\
\text { Motivation }\end{array}$ & $\begin{array}{l}\text { Intrinsic } \\
\text { Motivation }\end{array}$ & Purchase Intention \\
\hline \multirow{4}{*}{ Extrinsic } & Pearson & 1 & $692^{* * *}$ & $901^{* *}$ \\
\hline & Correlation & & & \\
\hline & Sig. (2-tailed) & & .000 & . 000 \\
\hline & $\mathrm{N}$ & 156 & 156 & 156 \\
\hline \multirow{3}{*}{ Intrinsic } & Pearson & $.692^{* *}$ & 1 & $.937^{* *}$ \\
\hline & Sig. (2-tailed) & .000 & & .000 \\
\hline & $\mathrm{N}$ & 156 & 156 & 156 \\
\hline \multirow{3}{*}{$\begin{array}{l}\text { Purchase } \\
\text { intention }\end{array}$} & Pearson & $.901^{* *}$ & $.937^{\text {t* }}$ & 1 \\
\hline & $\begin{array}{l}\text { Correlation } \\
\text { Sig (2-tailed) }\end{array}$ & & .000 & \\
\hline & $\mathrm{N}$ & 156 & 156 & 156 \\
\hline
\end{tabular}

**. Correlation is significant at the 0.01 level (2-tailed).

Fig. 4.5.1 CO-relation summary of intrinsic, extrinsic factors and motivation for purchasing frozen food

The correlation between motivation factor and the purchase intention of the frozen food was performed to identify whether there is any relation between them or not the correlation coefficient of extrinsic factors and purchase intention is found to be 0.901 . The p-value is significant at 0.000 , which indicates that the value is highly significant. Thus, it can be concluded that there is a positive and highly significant relationship between extrinsic motivation factors to purchase frozen food. Similarly, the coefficient correlation between the intrinsic motivations to purchase frozen food is found 0.937 it indicates that it is highly significantly correlated.

\section{Conclusions}

The present researcher has attempted to compare and contrast this work with that of a selected number of previously accomplished studies. In this respect, it was observed applicable to compare the present work with the work of Taneja, Hawa, Kanani, Sharma, Patel, and Siddhi. et al. (2014) and Sen and Antara (2019)

The present researcher shares close linkage with Taneja, Hawa, Kanani, Sharma, Patel, and Siddhi. et al. (2014). The researcher has attempted to find consumer purchase intention towards ready-to-eat food where socio-economic factors (age, gender, employment status, and education), various intrinsic factors, and intrinsic factors were studied to understand 
consumer perception on purchase intention. Study finding reveals that both the motivation factors play important role in Purchase intention, study further reveals that purchase intention dependent on Age, employment status, and education status. Moreover, the present research has revealed that there is a significant relationship between motivation factors (extrinsic and intrinsic) and purchase intention, the study discloses there no significant relationship between age, gender, and employment status, and purchase intention. Whereas the study unveiled, there is a significant relationship between education and purchase intention.

Another scholar, Sen and Antara (2019) has examined the factors influencing consumers' to Take Ready-made Frozen Food (RMFF) the study found that socioeconomic factors (gender; age; education level; family income; profession) demonstrate a positive impact on purchasing RMFF. It further identified that RMFF is currently expanding because it is easy to cook which is indicated by $94 \%$ of the respondent and safe (as indicated by $73 \%$ of respondents). Moreover, the brand image (indicated by $84 \%$ of respondents), quality (68\%), low pricing $(77 \%)$, advertising $(64 \%)$, appearance $(69 \%)$, availability $(59 \%)$, and taste $(78 \%)$. However, "time-saving (according to 38\% respondents)" and "packaging (indicated by $49 \%$ respondents)" factors do not have any significant impact on the purpose of buying Ready Made Frozen Food.

The study has shown that the majority of intrinsic and extrinsic factors had a positive influence on consumers' motivation to purchase frozen food, depending on the taste, value for money, nutrition, ingredients, quality, brand, advertisement, convenience, and education attract people to consume frozen food even more. Similarly, better awareness about the frozen products and the overall branding, and the process of the advertisement that takes on a place to make it a convenient product makes it more rewarding for the consumers and to keep purchasing these products. Likewise, to motivate the consumers to keep purchasing frozen food, the frozen food products must keep evolving, a better awareness campaign to develop.

Content analysis of the component indicates a positive relation in purchasing frozen food. From the consumer's perspective, the various factors come into place while they are to purchase and consume frozen food depending on the convenience and the nutritional factors. their view towards the frozen food product seems to be positive due to the convenience and the availability of the product all year long, which means the analysis of the variable state there is a strong relationship between consumers motivation with the intrinsic and extrinsic factors. 


\section{References}

Ahuja. H. K. (2011). A comparative study of attitude and adoption of frozen food amongst the consumers of Ludhiana and Delhi cities. Punjab Agricultural University, Ludhiana-141004.

Alba, J. W. (1983). The effects of product knowledge on comprehension, retention, and evaluation of product information. Advances in Consumer Research, 10,576-580

Archer, D. (2004). Freezing: An underutilized food safety technology? International Journal of food microbiology. 90, 127-38. 10.1016/S0168-1605(03)00215-0.

Armstrong, G., \& Kotler, P. (2007). Marketing: an introduction. New Jersy: Pearson Prentice Hall.

Becker, G. S. (1965), A theory of the allocation of time. Economic Journal, 75. 493-517.

Bettman, J. (1979). An information processing theory of consumer choice. Reading: Addison Wesley.

Blackwell, R. D. (2001). Consumer behaviour (9th ed.). USA: Harcourt College Publishers.

Cooper, C., \& Channon, D. (1998). The concise Blackwell encyclopedia of management. In Oxford. Wiley Blackwell.

Cooper, Schidler, D. (2006). Business research methods. McGraw-Hill Irwin.

Cummins, S. (2002). A systematic study of an urban foodscape: the price and availability of food in greater glasgow. MRC Social and Public Health Journal 39(11), 2115-2130

Darley, W. K., \& Smith, R. E. (1995), “Gender differences in information procession strategies: An empirical test of the selective model in advertising response", Journal of Advertising, 24(1), 41-56.

Dick, A, Jain, A. \& Richardson, P. (1996). How consumers evaluate store brands. Journal of Product \& Brand Management 5(2), 19-28.

Elizabeth, E. (1996). Typologies of compulsive buying behavior: a constrained clockwise regression approach. Journal of Consumer Psychology, 39(11), 231-261.

Encylopedia. (2003). Food and culture. Refrid from https:/ / www.encyclopedia.com/sportsand-everyday-life/food-and-drink/food-and-cooking/frozen-foods-industry

Amir, S. Vawaz, A. Raheem, A. R., Badar. K. (2014). Frozen food revolution: investigating how the availability of frozen food affects consumer buying behavior. International Journal of Economics, Commerce, and Management 2 (8).

Ghosh, A. (1990). Retail Management. Chicago: Dryden Press.

Hibic. S. \& Poturak. M. (2016). Impact of a Brand on Consumer Decision-making Process. European Journal of Economic Studies, 17 (3).

Hofmann, S. (2006). The market for organic food from the perspective of consumers and market actors. analysis of supply chain and demand. 
Muruganantham, G., \& Bhakat, R. S. (2013). A review of impulse buying behavior. International Journal of Marketing Studies, 5(3), 150-160 Jay, J. M. (2000). Modern food microbiology. Sixth Edition; Aspen Publication.

Kim, J. O., \& Jin, B. (2001). Korean consumers' patronage of discount stores: domestic vs. multinational discounted stored shoppers' profile. Journal of Consumer Marketing, 18(3).

Maslow, A. H. (1943). A theory of human motivation. Psychological Review 50 (4), 370-396.

Olson, R. L., \& Dietrich, W. C. (1968). Vegetables: characteristics and the stability of the frozen product. In the freezing preservation of Foods, (4th ed.) 2, Westport: Avi Publishing Co.

Patel. D., \& Rathod. R. (2017). Ready-to-eat food perception. Food preferences and food choice-a theoretical discussion. Worldwide Journal of Multidisciplinary Research and Development, 3(8). 198-205

Peter, J. P., \& Olson, J. C. (2008). Consumer behavior and marketing strategy (8 ed.). Newyork: Mcgraw-hill Inc.

Radman, M. (2005). Consumer consumption and perception of organic products in Croatia. British Food Journal, 107(4), 263-273.

Ramasamy, K., Kalaivavan, G., \& Sukumar, S. (2005). Consumer behavior towards instant food. Indian Journal of Marketing, 24-25.

Rani, P. (2014). Factor influencing consumer behavior. International Journal of Current Research and Academic Review, 2(9), 52-61.

Rook, D. W. (1995). Normative influence on impulse buying behavior. Journal of Consumer Research, 305-313.

Sen.S. \& Antara, N. (2018). Influencing factors to stay off-campus living by students. International Multidisciplinary Research Journal. 8, 40-44.

Schroetera, C. (2008). Determining the impact of food price and income change on buying behavior. Journal of Health Economics, 27(1), 45-68.

Solanki, S., \& Sheth, H. J. (2015). Healthy food selection: The role of nutritional information on packaged foods on consumers' purchase intentions. Indian Journal of Marketing, 45(9), 37-54. doi:10.17010/ijom/2015/v45/i9/79807

Solanki, S., \& Sheth (2015) Healthy Food Selection: The role of the nutritional information of Packaged foods on consumers' intention. Indian Journal of Marketing. 45(9), 37-54.

Solomon, M. R. (2006). Consumer Behaviour: Buying, Having, and Being. (7th ed.). New Jersey: Pearson Prentice Hall.

Solomon, M. R., Bamossy, G., \& Askegaard, S. (2002). Consumer Behaviour: A European Perspective. New Jersey: Pearson Prentice Hall. 
Vasegh. H. \& Kahemi. F. (2015) Study the socio-cultural and demographic factors influencing purchasing behavior of Shiraz Zarrin Ghazal Dairy Products Company. Science Journal (CSJ), 36,(3) Special Issue (https://kathmandupost.com/money/2020/11/29/ lockdown-leads-to-sales-boom-in-frozen-foods) Retrieved on 2020/12/10.

Zanoli, R. (2004). The European Consumer and Organic Food. Organic marketing initiatives.

Zeithaml, V. (1998). Consumer perception of price quality and value: A means-end model and synthesis of evidence. Journal of Marketing, 52(3), 48-62. 